\title{
ЗНАЧЕНИЕ ОДНОНУКЛЕОТИДНОГО ПОЛИМОРФИЗМА НЕКОТОРЫХ ГЕНОВ СИСТЕМЫ БИОТРАНСФОРМАЦИИ КСЕНОБИОТИКОВ В РАЗВИТИИ ОСТРОГО ПАНКРЕАТИТА
}

\author{
Т. А. Самгина 凶, П. М. Назаренко, А. В. Полоников, В. А. Лазаренко
}

Курский государственный медицинский университет, Курск, Россия

Генетически детерминированные особенности функционирования системы биотрансформации ксенобиотиков играют важную роль в развитии острого панкреатита (ОП) и его осложнений. Целью работы было определить вклад однонуклеотидных полиморфизмов генов CYP1A1 -462 Т>C rs1048943, CYP2E1 -1293 G>C rs3813867 и ABCB1 -3435 G>A rs1045642 в развитие ОП и его осложнений. Образцы ДНК получали от 547 неродственных больных ОП (154 женщины и 393 мужчины; средний возраст составил 48,9 \pm 13,1), находившихся на стационарном лечении в хирургических отделениях города Курска и 573 неродственных индивида без заболеваний ЖКТ (161 женщина и 412 мужчин; средний возраст - 47,8 \pm 12,1). Генотипирование полиморфизма изучаемых генов выполняли методом ПЦР путем дискриминации аллелей с помощью ТаqМап-зондов. У 97 пациентов развился инфицированный панкреонекроз (ИП), у 101 - псевдокиста (ПК), у 111 - гнойно-некротический перипанкреатит (ГНП). Установлено, что у носителей аллеля А гена $A B C B 1 \mathrm{G}>\mathrm{A}(\mathrm{rs} 1045642)$ чаще развивался ОП ( $p=0,0008)$, у носителей генотипа $\mathrm{G} / \mathrm{G}$ редко развивался как ОП ( $\left.p=5 \cdot 10^{-4}\right)$, так и его осложнения: ИП ( $\left.p=0,03^{\mathrm{R}}\right)$, ГНП ( $\left.p=0,036^{\mathrm{R}}\right)$, ПК ( $\left(\mathrm{p}=0,04^{\mathrm{R}}\right)$. Отсутствие длительного злоупотребления алкогольными напитками у носителей генотипов G/C-C/C CYP2E1 G>C (rs3813867) редко приводило к развитию ОП ( $p=0,03)$, у носителей генотипа G/C CYP2E1 (rs3813867) ( $p=0,050 D)$ чаще возникала псевдокиста. У носителей генотипа C/C CYP1A1 T>C (rs1048943) ОП чаще осложнялся ИП ( $\left.p=0,009^{\mathrm{R}}\right)$, ГНП ( $\left.p=0,003^{\mathrm{R}}\right)$, ПК ( $\left.p=0,003^{\circ}\right)$. В целом, для носителей генотипов G/G ABCB1 G>A (rs1045642) было характерно более легкое течение ОП, тяжелое течение было характерно для носителей C/C CYP1A1 T>C (rs1048943).

Ключевые слова: острый панкреатит, гены ферментов биотрансформации ксенобиотиков, генетический полиморфизм, rs1045642, rs1048943, rs3813867

Вклад авторов: Т. А. Самгина - написание статьи, разработка концепции и дизайна, анализ и интерпретация данных, реализация клинических и молекулярно-генетических методов исследования, статистическая обработка данных; П. М. Назаренко - руководство хирургической частью исследования, лечение и подбор больных в ОБУЗ КГКБ № 4; А. В. Полоников - руководство генетической частью исследования; В. А. Лазаренко - руководство исследованием.

Соблюдение этических стандартов: исследование одобрено этическим комитетом Курского государственного университета (протокол № 3 от 11 марта 2013 г.). Все участники исследования подписали добровольное информированное согласие.

$\bowtie$ Для корреспонденции: Татьяна Александровна Самгина

ул. К. Маркса, д. 3, 305000; г. Курск; tass@list.ru

Статья получена: 05.01.2020 Статья принята к печати: 08.02.2020 Опубликована онлайн: 15.02.2020

DOI: $10.24075 /$ vrgmu.2020.008

\section{THE ROLE OF SOME XENOBIOTIC BIOTRANSFORMATION GENES SNP IN THE DEVELOPMENT OF ACUTE PANCREATITIS}

Samgina TA $\bowtie$, Nazarenko PM, Polonikov AV, Lazarenko VA

Kursk State Medical University, Kursk, Russia

Genetically determined features of the xenobiotic biotransformation system play an important role in the development of acute pancreatitis (AP) and its complications. The aim of this study was to assess the contribution of 3 SNPs (CYP1A1 -462 T>C rs1048943, CYP2E1 -1293 G>C rs3813867 and ABCB1 -3435 G>A rs 1045642) to the development of AP and its complications. DNA samples were collected from 547 unrelated patients with AP (154 women and 393 men; mean age $48.9 \pm 13.1$ years) undergoing therapy at surgery departments of Kursk and 573 unrelated individuals without gastrointestinal diseases (161 women and 412 men; mean age $47.8 \pm 12.1$ years). The polymorphisms were genotyped by PCR using TaqMan probes for allele discrimination. Infected pancreatic necrosis (IPN) was observed in 97 patients; 101 patients developed a pseudocyst (PC); 111 patients had a peripancreatic necrosis (PN). AP was the most common in the carriers of the A allele in ABCB1 $\mathrm{G}>\mathrm{A}$ ( $\mathrm{rs1045642)}(p=0.0008)$. The carriers of the $\mathrm{G} / \mathrm{G}$ genotype rarely developed both $\mathrm{AP}\left(p=5 \cdot 10^{-4}\right)$ and its complications: IPN $\left(p=0.03^{\mathrm{R}}\right)$, PN $\left(p=0.036^{\mathrm{R}}\right)$, PC $\left(p=0.04^{\mathrm{R}}\right)$. The carriers of the $\mathrm{G} / \mathrm{C}-\mathrm{C} / \mathrm{C}$ CYP2E1 G>C (rs3813867) genotypes who had no long-term history of alcohol abuse rarely developed AP $(p=0.03)$. The carriers of the G/C CYP2E1 (rs3813867) genotype tended to develop pseudocysts $\left(p=0.05 \mathrm{O}^{\mathrm{D}}\right)$. AP was more frequently complicated by IPN $\left(p=0.009^{\mathrm{P}}\right)$, PN $\left(p=0.003^{\mathrm{R}}\right)$ and PC $\left(p=0.003^{\mathrm{D}}\right)$ in the carriers of the C/C CYP1A1 T>C (rs1048943) genotype. A milder course of AP was typical for the carriers of the $\mathrm{G} / \mathrm{G} A B C B 1 \mathrm{G}>\mathrm{A}$ (rs1045642) genotype; a more severe course was characteristic of the carriers of the C/C CYP1A1 T>C (rs1048943) genotype.

Keywords: acute pancreatitis, xenobiotic biotransformation enzyme genes, genetic polymorphism, rs1045642, rs1048943, rs3813867

Author contribution: Samgina TA conceived and designed the study, conducted clinical and molecular-genetic tests, analyzed and interpreted the obtained data, and wrote the manuscript; Nazarenko PM supervised surgical treatment and postoperative care at Kursk City Clinical Hospital № 4 and recruited patients for the study; Polonikov AV supervised genetic testing; Lazarenko VA supervised the study.

Compliance with ethical standards: the study was approved by the Ethics Committee of Kursk State Medical University (Protocol № 3 dated March 11, 2013). The patients gave informed consent to participate.

$\triangle$ Correspondence should be addressed: Tatiana A. Samgina

K. Marksa, 3, 305000; Kursk, tass@list.ru

Received: 05.01.2020 Accepted: 08.02.2020 Published online: 15.02.2020

DOI: $10.24075 /$ brsmu.2020.008

В последние годы проводят активные исследования действия химических токсинов из окружающей среды и нарушения регуляции процессов про- и антиоксидантной защиты в развитии острого панкреатита (ОП). Так, была выявлена ассоциация острого небилиарного панкреатита с курением [1], а у курящих и злоупотребляющих алкогольными напитками пациентов с ОП отмечен повышенный риск развития панкреонекроза [2]. Несмотря 
на многочисленные исследования, генетические механизмы реализации предрасположенности к ОП и его осложнениям пока изучены недостаточно, но очевидно, что генетически детерминированные особенности функционирования системы биотрансформации ксенобиотиков и антиоксидантной системы играют в этом важную роль.

Трансмембранный белок ABCB1 - член надсемейства АТФ-зависимых транспортеров лекарственных средств и ксенобиотиков с широкой субстратной специфичностью, отвечает за снижение накопления наркотиков в клетках с множественной лекарственной устойчивостью, часто опосредует развитие резистентности к противоопухолевым препаратам. Гены ABC делят на семь различных подсемейств. АВСВ1 является членом подсемейства MDR/TAP, локализован на 7q21.12. Ген экспрессируется в большей степени в яичках, мышцах, желудке и поджелудочной железе. Была изучена роль гена ABCB1 в развитии колоректального рака [3, 4], однако статистически значимых ассоциаций выявлено не было. Роль гена при ОП ранее не изучали.

На сегодняшний день наиболее изучена система оксидазы цитохрома Р450, включающая CYP1, CYP2 и CYP3, которые в целом отвечают за расщепление чужеродных соединений у млекопитающих.

Обнаружено увеличение активности ферментов фазы активации у больных с нарушенной функцией поджелудочной железы за счет полиморфизма генов цитохрома P450, CYP1A1, CYP2E1 [5]. По мнению авторов, основную причастность к развитию панкреатита имеет CYP1A1, который запускает каскад протеинкиназы с увеличением репликации ДНК и тканевой пролиферации, генерирует радикалы кислорода, образует реактивные промежуточные продукты метаболизма ксенобиотиков и способен активировать многие канцерогены.

Известно, что CYP1A1 (ароматическая соединительноиндуцируемая арилгидрокарбонгидроксилаза) в первой фазе биотрансформации ксенобиотиков превращает полициклические ароматические углеводороды в высокоактивные мутагенные метаболиты. Ген, кодирующий ключевой фермент, локализован на 15q24.1. Известно 19 вариантов полиморфизма гена, играющих определенную роль в развитии онкологических и профессиональных заболеваний [6].

CYP2E1 (цитохром P450 2Е1) кодирует белки цитохрома P450 (монооксигеназы), которые катализируют многие реакции, связанные с метаболизмом лекарственных средств и синтезом холестерина, стероидов и других липидов. Этот белок локализован в эндоплазматическом ретикулуме, его индуцируют действие этанола, диабетическое состояние и голодание. Фермент участвует в метаболизме этанола, ацетона, бензола, этиленгликоля, а также премутагенов, обнаруженных в сигаретном дыме [7]. Ген локализован на 10q26.3, экспрессируется в большей степени в жировой ткани, слизистой оболочке пищевода, периферической крови.

При сравнении частоты генотипов и аллелей $A D H 2$, ADH3, ALDH2, CYP2E1, IL1, IL6, IL8 и TNF у пациентов с хроническим панкреатитом, алкогольным циррозом печени и у здоровых индивидов было обнаружено, что частота CYP2E1 и ALDH2 была значительно ниже, чем в контроле [8]. В то же время не обнаружена связь между полиморфизмом CYP2E1 и алкогольным панкреатитом в азиатской популяции $[9,10]$. Носители генотипа m2/ m2 CYP1A1 могут быть более склонны к развитию алкогольного цирроза и алкогольного панкреатита [11]. Установлена связь полиморфизма P450 CYP1A1 lle105Val c повышенным риском развития хронического панкреатита [12]. В результате транзиции $A \rightarrow G$, приводящей к замене изолейцина на валин в кодоне 462 молекулы цитохрома (lle462Val), активность продуцируемого фермента увеличивается в два раза по сравнению с исходным белком, что может привести к увеличению концентрации недоокисленных промежуточных токсичных метаболитов и накоплению свободных радикалов [13-15].

Таким образом, полиморфные варианты генов ферментов биотрансформации ксенобиотиков могут иметь отношение к развитию ОП. Целью работы было определить связь ОНП генов СУР1A1 -462 Т>C rs1048943, CYP2E1 -1293 G>C rs3813867 и ABCB1 -3435 G>A rs1045642 c развитием ОП и его осложнений.

\section{ПАЦИЕНТЫ И МЕТОДЫ}

Образцы ДНК для исследования получали от 547 неродственных больных ОП (154 женщины и 393 мужчины), находившихся на стационарном лечении в хирургических отделениях города Курска в период 2012-2015 гг., и 573 неродственных индивида без заболеваний ЖКТ (161 женщина и 412 мужчин). Средний возраст больных составил 48,9 $\pm 13,1$, здоровых лиц $47,8 \pm 12,1$. Критерии включения пациентов в основную группу: 1) установленный диагноз острого панкреатита; 2) возраст 18-80 лет; 3) отсутствие патологии органов билиарной системы: желчно-каменной болезни, пороков развития ПЖ (pancreas divisum), травм поджелудочной железы, в том числе операционной или после эндоскопических манипуляций; 4) отсутствие в анамнезе приема панкреатотоксичных лекарственных препаратов (гипотиазида, НПВС, стероидных противовоспалительных средств), аутоиммунных, инфекционных, аллергических заболеваний (лаки, краски), дисгормональных процессов при беременности и менопаузе, заболеваний близлежащих органов ЖКТт; 5) отсутствие наследственной отягощенности по ОП. Критерии исключения: несоответствие критериям включения.

Диагноз ОП устанавливали с использованием современной классификации ОП, разработанной Российским обществом хирургов в 2014 г. с учетом классификации Атланта-92 и еe модификаций, предложенных в г. Кочин в 2011 г. Международной ассоциацией панкреатологов и Международной рабочей группой по классификации острого панкреатита $[16,17]$ с использованием общеклинических, лабораторных (общий и биохимический анализ крови) и инструментальных методов исследования (УЗИ и МРТ поджелудочной железы, эзофагогастродуоденоскопии).

При анкетировании участников исследования у всех пациентов учитывали наличие вредных привычек курения и злоупотребления алкоголем как основных факторов риска развития ОП [18, 19].

В зависимости от количества потребляемого алкоголя в неделю участников исследования подразделили на две группы: 1) лица, употреблявшие алкоголь менее 200 г в перерасчете на этанол в неделю; 2) лица, употреблявшие алкоголь более 200 г в перерасчете на этанол в неделю. Данное значение выбрали в качестве порогового, так как оно представляет собой медиану (в граммах чистого этанола) среди максимальных уровней «безопасного потребления алкоголя» (safe alcohol intake) в неделю, 
одобренного во многих странах в соответствии с национальными рекомендациями по уровню потребления спиртных напитков [20]. По частоте употребления алкоголя участники исследования были разделены на две группы: 1) лица, употребляющие алкоголь 1-2 дня в месяц или реже; 2) лица, употребляющие алкоголь 1 день или более в неделю. Согласно стажу употребления алкоголя все пациенты были разделены на две группы: 1) лица с продолжительностью употребления алкоголя до 10 лет; 2) лица, употребляющие алкоголь в течение 10 лет или более.

У пациентов проводили забор цельной венозной крови объемом 5-10 мл в пластиковые пробирки с 0,5 М ЭДТА. Затем кровь замораживали и хранили в морозильных камерах при температуре $-20{ }^{\circ} \mathrm{C}$ до выделения геномной ДНК. Выделение ДНК проводили стандартным двухэтапным методом фенольно-хлороформной экстракции и преципитации этанолом. Сначала проводили лизис лейкоцитов. Для этого лейкоцитарную массу, осажденную дважды центрифугированием с Naфосфатным буфером (pH = 7,8), подвергали лизису в растворе, содержащем ТЕ-буфер, протеиназу K и 0,4\% додецилсульфат натрия (SDS) в течение 12 ч при температуре $42{ }^{\circ} \mathrm{C}$. Затем из полученного клеточного лизата выделяли геномную ДНК: сначала с помощью фенола и 10 мМ Трис-HCl (pH = 8,0), затем фенола и хлороформа (в соотношении 1: 1) и на заключительном этапе - хлороформа. Геномную ДНК преципитировали ледяным 96\%-м этанолом, высушивали на воздухе, растворяли в ТЕ-буфере, измеряли концентрацию ДНК, замораживали при температуре $-20{ }^{\circ} \mathrm{C}$ до выполнения генотипирования ДНК-полиморфизмов.

Генотипирование CYP1A1 -462 T>C rs1048943, CYP2E1 -1293 G>C rs3813867 и ABCB1 -3435 G>A rs1045642 проводили методом ПЦР в режиме реального времени путем дискриминации аллелей с помощью TaqMan-зондов на амплификаторе CFX96 (Bio-Rad Laboratories; CША) с использованием коммерческих наборов реактивов TaqMan SNP Genotyping Assays (Applied Biosystems; США). Повторное генотипирование 10\% исследованных образцов, отобранных по случайному принципу и при отсутствии информации о статусе болезни, показало 100\%-ю воспроизводимость оригинальных результатов. Для сравнения категориальных переменных между группами использовали критерий $\chi^{2}$ Пирсона, для сравнения количественных переменных - критерии Стьюдента (для нормально распределенных признаков) и Манна-Уитни (для признаков, отличных от нормальных). Для анализа соответствия распределения частот генотипов равновесию Харди-Вайнберга (РХВ) и сравнения частот аллелей и генотипов между группами использовали критерий $\chi^{2}$ Пирсона. Ассоциации аллелей и генотипов с риском развития панкреатита оценивали по величине отношения шансов (OR). Статистический анализ осуществляли с использованием программы Statistica 6.0 (StatSoft; CША).

\section{РЕЗУЛЬТАТЫ ИССЛЕДОВАНИЯ}

Ассоциации изучаемых полиморфизмов генов CYP1A1 Т>C и CYP2E1 G>C с риском развития ОП не были обнаружены (табл. 1).

Носители аллеля А гена ABCB1 G>A (rs1045642) обладали повышенным риском развития ОП, а носители генотипа $\mathrm{G} / \mathrm{G}$, напротив, пониженным.

При отсутствии длительного злоупотребления алкогольными напитками носители генотипов G/C-C/C CYP2E1 G>C (rs3813867) редко страдали ОП (табл. 2).

Носители генотипов C/C CYP1A1 T>C (rs1048943) чаще страдали инфицированным панкреонекрозом, в отличие от носителей генотипов G/G ABCB1 G>A (rs1045642) (табл. 3).

У носителей генотипов C/C CYP1A1 T>C (rs1048943) и G/C CYP2E1 (rs3813867) чаще развивалась ПK, а G/G ABCB1 G>A rs1045642 - реже (табл. 4).

Наиболее часто ОП осложняло развитие ГНП у носителей генотипа C/C CYP1A1 T>C (rs1048943) и редко у носителей генотипа G/G ABCB1 G>A (rs1045642) (табл. 5).

\section{ОБСУЖДЕНИЕ РЕЗУЛЬТАТОВ}

В процесс биотрансформации, включающий ферментативное превращение чужеродных включений, или ксенобиотиков, и состоящий из трех фаз: активации, собственно детоксикации и выведения, вовлечено множество ферментов [21, 22]. Роль генов ФБК (CYP2E1 и CYP1A1) В развитии алкогольного панкреатита и цирроза печени изучали у употребляющих алкогольные напитки бразильцев; ассоциации с панкреатитом установлено не было [11].

Известно, что цитохромы Р450 осуществляют биоактивацию полициклических ароматических

Таблица 1. Анализ ассоциации аллелей и генотипов полиморфных вариантов генов ферментов биотрансформации ксенобиотиков и антиоксидантной системы с риском развития ОП (кодоминантная модель)

\begin{tabular}{|c|c|c|c|c|c|}
\hline \multirow{2}{*}{$\begin{array}{c}\text { Ген } \\
\text { (SNP ID) }\end{array}$} & \multirow{2}{*}{ Генотип, аллель } & \multicolumn{2}{|c|}{$n(\%)$} & \multirow{2}{*}{$p$} & \multirow{2}{*}{ cor $\mathrm{OR}(95 \% \mathrm{Cl})$} \\
\hline & & Здоровые $(n=573)$ & Больные $(n=547)$ & & \\
\hline \multirow{4}{*}{$\begin{array}{l}\text { CYP1A1 -462 T>C } \\
\text { (rs1048943) }\end{array}$} & $T / T$ & $507(91,0)$ & $489(90,2)$ & \multirow{3}{*}{0,07} & 1,00 \\
\hline & $\mathrm{T} / \mathrm{C}$ & $49(8,8)$ & $46(8,5)$ & & $0,97(0,64-1,48)$ \\
\hline & $\mathrm{C} / \mathrm{C}$ & $1(0,2)$ & $7(1,3)$ & & $7,26(0,89-59,21)$ \\
\hline & C & 0,05 & 0,06 & 0,3 & $1,22(0,83-1,79)$ \\
\hline \multirow{4}{*}{$\begin{array}{l}\text { CYP2E1 -1293 G>C } \\
\text { (rs3813867) }\end{array}$} & $\mathrm{G} / \mathrm{G}$ & $532(95,0)$ & $513(94,0)$ & \multirow{3}{*}{0,46} & 1,00 \\
\hline & $\mathrm{G} / \mathrm{C}$ & $22(3,9)$ & $29(5,3)$ & & $1,37(0,78-2,41)$ \\
\hline & $\mathrm{C} / \mathrm{C}$ & $6(1,1)$ & $4(0,7)$ & & $0,69(0,19-2,46)$ \\
\hline & C & 0,03 & 0,034 & 0,64 & $1,12(0,70-1,80)$ \\
\hline \multirow{4}{*}{ 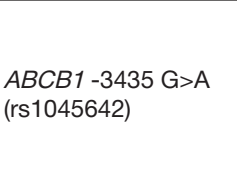 } & $\mathrm{A} / \mathrm{A}$ & $158(28,3)$ & $183(33,5)$ & \multirow{3}{*}{$5 \cdot 10^{-4}$} & 1,00 \\
\hline & $\mathrm{G} / \mathrm{A}$ & $269(48,2)$ & $284(52,0)$ & & $0,91(0,70-1,19)$ \\
\hline & $\mathrm{G} / \mathrm{G}$ & $131(23,5)$ & $79(14,5)$ & & $0,52(0,37-0,74)$ \\
\hline & A & 0,52 & 0,6 & 0,0008 & $1,33(1,13-1,58)$ \\
\hline
\end{tabular}


углеводородов. Установлено, что CYР1A1 отсутствует в нормальной ткани, а экспрессируется лишь под действием ксенобиотиков. Обнаруженная нами ассоциация генотипа C/C CYP1A1 T>C (rs1048943) с повышенным риском развития ОП, возможно, свидетельствует об изменении активности фермента и увеличении концентрации недоокисленных токсичных метаболитов, агрессивно влияющих на ткань поджелудочной железы.

Роль полиморфизмов гена СYР2E1 в развитии острого панкреатита до настоящего времени не изучали, но опубликованы данные о том, что минорный аллель CYP2E1 может обладать протективным эффектом при отравлении метанолом [23]. В нашем исследовании носители генотипов G/C CYP2E1 (rs3813867) чаще страдали ОП, однако при отсутствии воздействия фактора риска злоупотребления алкогольными напитками более 10 лет носители генотипов G/C-C/C CYP2E1 G>C (rs3813867) были устойчивее к воздействию алкоголя и редко страдали ОП.

Ген АВСВ1 кодирует Р-гликопротеин, который является эффлюксным транспортером и участвует в выведении ксенобиотиков, препятствуя их накоплению в органах и тканях [24]. Изучение вклада полиморфного варианта rs1045642 гена ABCB1 в развитие артериальной гипертензии и оценка результатов лечения амлодипином в различных популяциях [25-27] показали высокий антигипертензивный эффект в группе ТТ, который авторы объяснили снижением экспрессии ABCB1. Те же авторы обнаружили связь генотипа Т с более высоким риском геморрагических осложнений при приеме дабигатрана после артропластики коленного сустава. Полученные нами результаты свидетельствуют о том, что снижение экспрессии ABCB1 негативно отражается на способности к детоксикации алкоголя и у носителей аллеля А повышает риск развития ОП.

В целом, более легкое течение ОП было характерно для носителей генотипов $\mathrm{G} / \mathrm{G}$ ABCB1 G>A (rs1045642), тяжелое - для носителей C/C CYP1A1 T>C (rs1048943).

\section{ВЫВОДЫ}

Проведенное нами изучение вклада ОНП генов ферментов биотрансформации ксенобиотиков в развитие ОП у жителей Курской области позволило не только выявить

Таблица 2. Анализ ассоциации аллелей и генотипов полиморфных вариантов генов ферментов биотрансформации ксенобиотиков и антиоксидантной системы с риском развития ОП (кодоминантная модель)

\begin{tabular}{|c|c|c|c|c|c|c|}
\hline \multirow{2}{*}{ Генотипы } & \multicolumn{3}{|c|}{ Отсутствие фактора риска $(f-)$} & \multicolumn{3}{|c|}{ Наличие фактора риска $\left(f_{+}\right)^{3}$} \\
\hline & Здоровые & Больные & OR $(95 \% \mathrm{Cl})_{\text {inter }} P 1$ & Здоровые & Больные & $\mathrm{OR}(95 \% \mathrm{Cl})_{\text {inter }} P 1$ \\
\hline \multicolumn{7}{|c|}{ CYP2E1 (rs3813867) } \\
\hline G/G & $119(90,8)$ & $173(96,6)$ & \multirow{2}{*}{$\begin{array}{c}0,34 \\
(0,13-0,94) \\
0,03\end{array}$} & $98(96,1)$ & $116(95,1)$ & \multirow{2}{*}{$\begin{array}{c}1,27 \\
(0,35-4,62) \\
0,72^{D}\end{array}$} \\
\hline $\mathrm{G} / \mathrm{C}-\mathrm{C} / \mathrm{C}$ & $12(9,2)$ & $6(3,4)$ & & $4(3,9)$ & $6(4,9)$ & \\
\hline
\end{tabular}

Примечание: ${ }_{\text {inte }} p-$ - уровень значимости, достигнутый при анализе взаимодействия SNP и фактора риска; наличие фактора риска $\left(f_{+}\right)^{3}-$ длительность употребления алкоголя более 10 лет.

Таблица 3. Анализ ассоциации генотипов полиморфных вариантов изучаемых генов с риском развития инфицированного панкреонекроза (наиболее значимые модели)

\begin{tabular}{|c|c|c|c|c|c|}
\hline \multirow[b]{2}{*}{ Ген (SNP ID) } & \multirow[b]{2}{*}{ Генотип, аллель } & \multicolumn{2}{|r|}{$n(\%)$} & \multirow[b]{2}{*}{$p^{1}$} & \multirow[b]{2}{*}{ cor $\mathrm{OR}(95 \% \mathrm{Cl})^{2}$} \\
\hline & & $\begin{array}{c}\text { Контрольная группа } \\
(n=573)\end{array}$ & $\begin{array}{c}\text { Больные с инфицированным } \\
\text { панкреонекрозом }(n=97)\end{array}$ & & \\
\hline \multirow{2}{*}{$\begin{array}{l}\text { CYP1A1-462 T>C } \\
\text { rs1048943 }\end{array}$} & $\mathrm{T} / \mathrm{T}-\mathrm{T} / \mathrm{C}$ & $556(99,8 \%)$ & $93(96,9 \%)$ & \multirow{2}{*}{$0,0095^{R}$} & 1,00 \\
\hline & $\mathrm{C} / \mathrm{C}$ & $1(0,2 \%)$ & $3(3,1 \%)$ & & $15,65(1,61-152.54)$ \\
\hline \multirow{2}{*}{$\begin{array}{l}A B C B 1-3435 \mathrm{G}>A \\
\text { rs1045642 }\end{array}$} & $\mathrm{A} / \mathrm{A}-\mathrm{G} / \mathrm{A}$ & $427(76,5 \%)$ & $82(85,4 \%)$ & \multirow{2}{*}{$0,036^{\mathrm{R}}$} & 1,00 \\
\hline & $\mathrm{G} / \mathrm{G}$ & $131(23,5 \%)$ & $14(14,6 \%)$ & & $0,54(0,30-0,99)$ \\
\hline
\end{tabular}

Таблица 4. Анализ ассоциации генотипов полиморфных вариантов изучаемых генов с риском развития псевдокисты при ОП (наиболее значимая модель)

\begin{tabular}{|c|c|c|c|c|c|}
\hline \multirow{2}{*}{$\begin{array}{c}\text { Ген } \\
\text { (SNP ID) }\end{array}$} & \multirow[b]{2}{*}{ Генотип, аллель } & \multicolumn{2}{|c|}{$n(\%)$} & \multirow[b]{2}{*}{$p^{1}$} & \multirow[b]{2}{*}{ cor $\mathrm{OR}(95 \% \mathrm{Cl})$} \\
\hline & & $\begin{array}{c}\text { Контрольная группа } \\
(n=573)\end{array}$ & $\begin{array}{c}\text { Больные с наличием ПК } \\
(n=101)\end{array}$ & & \\
\hline \multirow{2}{*}{$\begin{array}{l}\text { CYP1A1 -462 T>C } \\
\text { rs1048943 }\end{array}$} & $T / T-T / C$ & $556(99,8 \%)$ & $97(96 \%)$ & \multirow{2}{*}{$0,003^{\mathrm{D}}$} & 1.00 \\
\hline & $\mathrm{C} / \mathrm{C}$ & $1(0,2 \%)$ & $4(4 \%)$ & & $18,36(2,03-166,52)$ \\
\hline \multirow{2}{*}{$\begin{array}{l}\text { CYP2E1-1293 G>C } \\
\text { rs3813867 }\end{array}$} & $\mathrm{G} / \mathrm{G}-\mathrm{C} / \mathrm{C}$ & $538(96,1 \%)$ & $92(91,1 \%)$ & \multirow{2}{*}{$0,05^{\circ D}$} & 1.00 \\
\hline & $\mathrm{G} / \mathrm{C}$ & $22(3,9 \%)$ & $9(8,9 \%)$ & & $2,43(1,07-5,56)$ \\
\hline \multirow{2}{*}{$\begin{array}{l}A B C B 1-3435 \mathrm{G}>\mathrm{A} \\
\mathrm{rs} 1045642\end{array}$} & $\mathrm{~A} / \mathrm{A}-\mathrm{G} / \mathrm{A}$ & $427(76,5 \%)$ & $86(85,2 \%)$ & \multirow{2}{*}{$0,04^{\mathrm{R}}$} & 1,00 \\
\hline & $\mathrm{G} / \mathrm{G}$ & $131(23,5 \%)$ & $15(14,8 \%)$ & & $0,55(0,30-0,99)$ \\
\hline
\end{tabular}

Таблица 5. Анализ ассоциации генотипов полиморфных вариантов изучаемых генов с риском развития ГНП (наиболее значимые модели)

\begin{tabular}{|c|c|c|c|c|c|}
\hline \multirow{2}{*}{$\begin{array}{c}\text { Ген } \\
(\text { SNP ID) }\end{array}$} & \multirow[b]{2}{*}{ Генотип, аллель } & \multicolumn{2}{|c|}{$n(\%)$} & \multirow[b]{2}{*}{$p^{1}$} & \multirow[b]{2}{*}{${ }_{\text {cor }} \mathrm{OR}(95 \% \mathrm{Cl})$} \\
\hline & & $\begin{array}{c}\text { Контрольная группа } \\
(n=573)\end{array}$ & $\begin{array}{c}\text { Больные с ГНП } \\
(n=111)\end{array}$ & & \\
\hline \multirow{2}{*}{$\begin{array}{l}\text { CYP1A1-462 T>C } \\
\text { rs1048943 }\end{array}$} & $\mathrm{T} / \mathrm{T}-\mathrm{T} / \mathrm{C}$ & $556(99,8 \%)$ & $106(96,4 \%)$ & \multirow{2}{*}{$0,003^{R}$} & 1,00 \\
\hline & $\mathrm{C} / \mathrm{C}$ & $1(0,2 \%)$ & $4(3,6 \%)$ & & $18,00(1,99-163,22)$ \\
\hline \multirow{2}{*}{$\begin{array}{l}A B C B 1-3435 \mathrm{G}>A \\
\text { (rs1045642) }\end{array}$} & $\mathrm{A} / \mathrm{A}-\mathrm{G} / \mathrm{A}$ & $427(76,5 \%)$ & $94(85,5 \%)$ & \multirow{2}{*}{$0,03^{R}$} & 1,00 \\
\hline & $\mathrm{G} / \mathrm{G}$ & $131(23,5 \%)$ & $16(14,6 \%)$ & & $0,56(0,31-0,98)$ \\
\hline
\end{tabular}


ассоциации генотипов с развитием ОП и его осложнений, но и установить триггерное влияние факторов риска на развитие заболевания у носителей определенных генотипов.

Основываясь на анализе генетических факторов, таких как полиморфные варианты генов ферментов биотрансформации ксенобиотиков, можно осуществлять прогнозирование вероятности развития ОП и особенностей его клинического течения, что открывает возможности ранней диагностики болезни и проведения необходимых просилактических мероприятий по ее предупреждению. Исследование генетических полиморфизмов может оказаться полезным для прогнозирования исходов заболевания и разработки персонализированных подходов к лечению и профилактике.

\section{Литература}

1. Setiawan VW, Pandol SJ, Porcel J, Wilkens LR, Le Marchand L, Pike MC, et al. Prospective Study of Alcohol Drinking, Smoking, and Pancreatitis: The Multiethnic Cohort. Pancreas. 2016; 45 (6): 819-25.

2. Ali UA, Issa $Y$, Hagenaars JC, Bakker OJ, van Goor $H$ Nieuwenhuijs VB, Schaapherder AF. Risk of recurrent pancreatitis and progression to chronic pancreatitis after a first episode of acute pancreatitis. Clinical gastroenterology and hepatology. 2016; 14 (5): 738-46.

3. Mrozikiewicz-Rakowska B, Malinowski M, Nehring P, BartkowiakWieczorek J, Bogacz A, Żurawińska-Grzelka E, et al. The MDR1/ ABCB1 gene rs 1045642 polymorphism in colorectal cancer. Archives of Medical Science. 2017; 13 (1).

4. Zhao L, Li K, Li W, Yang Z. Association between the C3435T polymorphism of ABCB1/MDR1 gene (rs1045642) and colorectal cancer susceptibility. Tumor Biology. 2013; 34 (3): 1949-57.

5. ВинникЮ. С., Черданцев Д. В., Маркова Е. В., Коноваленко А. Н., Первова О. В., Миллер М. С. Генетические аспекты панкреатита. Сибирский медицинский журнал (Иркутск). 2004; 43 (2).

6. Hosagrahara VP, Rettie AE, Hassett C, Omiecinski CJ. Functional analysis of human microsomal epoxide hydrolase genetic variants. Chem Biol Interact. 2004; (150): 149-59.

7. Wang $\mathrm{X}$, Cheung CM, Lee WY, Or PM, Yeung JH. Major tanshinones of Danshen (Salvia miltiorrhiza) exhibit different modes of inhibition on human CYP1A2, CYP2C9, CYP2E1 and CYP3A4 activities in vitro. Phytomedicine. 2010; 17 (11): 868-75.

8. Kim MS, Lee DH, Kang HS, Park HS, Jung S, Lee JW, et al. Genetic polymorphisms of alcohol-metabolizing enzymes and cytokines in patients with alcohol induced pancreatitis and alcoholic liver cirrhosis. Korean J Gastroenterol. 2004; (43): 355-63.

9. Frenzer A, Butler WJ, Norton ID, Wilson JS, Apte MV, Pirola RC, et al. Polymorphism in alcohol-metabolizing enzymes, glutathione S-transferases and apolipoprotein E and susceptibility to alcoholinduced cirrhosis and chronic pancreatitis. J Gastroenterol Hepatol. 2002; (17): 177-82.

10. Yang B, O'Reilly DA, Demaine AG, Kingsnorth AN. Study of polymorphisms in the CYP2E1 gene in patients with alcoholic pancreatitis. Alcohol. 2001; (23): 91-7.

11. Burim RV, Canalle R, Martinelli Ade L, Takahashi C. Polymorphisms in glutathione S-transferases GSTM1, GSTT1 and GSTP1 and cytochromes P450 CYP2E1 and CYP1A1 and susceptibility to cirrhosis or pancreatitis in alcoholics. Mutagenesis. 2004; (19): 291-8.

12. Натальский А. А., Богомолов А. Ю., Андрианова К. В. Полиморфизм генов у больных хроническим панкреатитом. В сборнике: Теория и практика современной хирургии: Материалы X Всероссийской конференции общих хирургов; Рязань, 2018; с. 219-220.

13. Smithies AM, Sargen K, Demaine AG, Kingsnorth AN. Investigations of the interleukin 1 gene cluster and its association with acute pancreatitis. Pancreas. 2000; 20 (3): 234-40.

14. Teich N, Bauer N, Mössner J, Keim V. Mutational screening of patients with nonalcoholic chronic pancreatitis: identification of further trypsinogen variants. The American journal of gastroenterology. 2002; 97 (2): 341-6.

15. Ulrich AB, Standop J, Schmied BM, Schneider MB, Lawson TA, Pour PM. Species differences in the distribution of drugmetabolizing enzymes in the pancreas. Toxicologic pathology. 2002; 30 (2): 247-53.

16. Dellinger EP, Forsmark CE, Layer P, Levy P, Maravi-Poma E, Petrov MS, et al. Determinant-based classification of acute pancreatitis severity: an international multidisciplinary consultation. Ann Surg. 2012; 256 (6): 875-80.

17. Banks PA, Bollen TL, Dervenis C, Gooszen HG, Johnson CD, Sarr MG, et al. Acute Pancreatitis Classification Working Group. Classification of acute pancreatitis 2012: revision of the Atlanta classification and definitions by international consensus. Gut. 2013; 62 (1): 102-11.

18. Кляритская И. Л., Работягова Ю. С. Новые факторы риска развития хронического панкреатита. Крымский терапевтический журнал. 2012; (2): 63-69.

19. Лазаренко В. А., Антонов А. Е. Современное состояние проблемы вредных привычек как фрактора риска развития панкреатита. Социальные аспекты здоровья населения. 2017; 55 (3).

20. Furtwængler NA, de Visser RO. Lack of international consensus in low-risk drinking guidelines. Drug and alcohol review. 2013; 32 (1): 11-18.

21. Баранов В. С., Баранова Е. В., Иващенко Т. Э., Асеев М. В. Геном человека и гены «предрасположенности»: введение в предиктивную медицину. СПб.: Интермедика, 2000; 271 с.

22. Спицын В. А., Макаров С. В., Пай Г. В., Бычковская Л. С. Полиморфизм в генах человека, ассоциирующихся с биотрансформацией ксенобиотиков. Вестник ВОГиС. 2006; 10 (1): 97-105.

23. Hubacek JA, Zakharov S. Response to 'CYP2E1 Polymorphism and Better Outcome After Methanol Poisoning'. Basic and clinical pharmacology and toxicology. 2015; 117 (1): 3-4.

24. Marzolini C, Paus E, Buclin T, Kim RB. Polymorphisms in human MDR1 (P-glycoprotein): recent advances and clinical relevance. Clinical Pharmacology and Therapeutics. 2004; 75 (1): 13-33.

25. Guo HQ, Zhang GN, Wang YJ, Zhang YK, Sodani K, Talele T, Chen ZS. $\beta$-Elemene, a compound derived from Rhizoma zedoariae, reverses multidrug resistance mediated by the ABCB1 transporter. Oncology reports. 2014; 31 (2): 858-66.

26. Sychev DA, Levanov AN, Shelekhova TV, Bochkov PO, Denisenko NP, Ryzhikova KA, Kozlov AV. The impact of ABCB1 (rs1045642 and rs4148738) and CES1 (rs2244613) gene polymorphisms on dabigatran equilibrium peak concentration in patients after total knee arthroplasty. Pharmacogenomics and Personalized Medicine. 2018; (11): 127.

27. Sychev D, Shikh N, Morozova T, Grishina E, Ryzhikova K, Malova E. Effects of ABCB1 rs1045642 polymorphisms on the efficacy and safety of amlodipine therapy in Caucasian patients with stage I-II hypertension. Pharmacogenomics and personalized medicine. 2018; (11): 157. 


\section{References}

1. Setiawan VW, Pandol SJ, Porcel J, Wilkens LR, Le Marchand L, Pike MC, et al. Prospective Study of Alcohol Drinking, Smoking, and Pancreatitis: The Multiethnic Cohort. Pancreas. 2016; 45 (6): 819-25.

2. Ali UA, Issa $Y$, Hagenaars JC, Bakker OJ, van Goor $H$, Nieuwenhuijs VB, Schaapherder AF. Risk of recurrent pancreatitis and progression to chronic pancreatitis after a first episode of acute pancreatitis. Clinical gastroenterology and hepatology. 2016; 14 (5): 738-46.

3. Mrozikiewicz-Rakowska B, Malinowski M, Nehring P, BartkowiakWieczorek J, Bogacz A, Żurawińska-Grzelka E, et al. The MDR1/ ABCB1 gene rs 1045642 polymorphism in colorectal cancer. Archives of Medical Science. 2017; 13 (1).

4. Zhao L, Li K, Li W, Yang Z. Association between the C3435T polymorphism of ABCB1/MDR1 gene (rs1045642) and colorectal cancer susceptibility. Tumor Biology. 2013; 34 (3): 1949-57.

5. Vinnik YuS, Cherdancev DV, Markova EV, Konovalenko AN Pervova OV, Miller MS. Geneticheskie aspekty pankreatita. Sibirskij medicinskij zhurnal (Irkutsk). 2004; 43 (2). Russian.

6. Hosagrahara VP, Rettie AE, Hassett C, Omiecinski CJ. Functional analysis of human microsomal epoxide hydrolase genetic variants. Chem Biol Interact. 2004; (150): 149-59.

7. Wang $X$, Cheung CM, Lee WY, Or PM, Yeung JH. Major tanshinones of Danshen (Salvia miltiorrhiza) exhibit different modes of inhibition on human CYP1A2, CYP2C9, CYP2E1 and CYP3A4 activities in vitro. Phytomedicine. 2010; 17 (11): 868-75.

8. Kim MS, Lee DH, Kang HS, Park HS, Jung S, Lee JW, et al. Genetic polymorphisms of alcohol-metabolizing enzymes and cytokines in patients with alcohol induced pancreatitis and alcoholic liver cirrhosis. Korean J Gastroenterol. 2004; (43): 355-63.

9. Frenzer A, Butler WJ, Norton ID, Wilson JS, Apte MV, Pirola RC, et al. Polymorphism in alcohol-metabolizing enzymes, glutathione S-transferases and apolipoprotein E and susceptibility to alcoholinduced cirrhosis and chronic pancreatitis. J Gastroenterol Hepatol. 2002; (17): 177-82.

10. Yang B, O'Reilly DA, Demaine AG, Kingsnorth AN. Study of polymorphisms in the CYP2E1 gene in patients with alcoholic pancreatitis. Alcohol. 2001; (23): 91-7.

11. Burim RV, Canalle R, Martinelli Ade L, Takahashi C. Polymorphisms in glutathione S-transferases GSTM1, GST1 1 and GSTP1 and cytochromes P450 CYP2E1 and CYP1A1 and susceptibility to cirrhosis or pancreatitis in alcoholics. Mutagenesis. 2004; (19): 291-8.

12. Natalskij AA, Bogomolov AYu, Andrianova KV. Polimorfizm genov u bol'nyh hronicheskim pankreatitom. $V$ sbornike: Teorija i praktika sovremennoj hirurgii: Materialy X Vserossijskoj konferencii obshhih hirurgov; Rjazan', 2018; s. 219-220. Russian.

13. Smithies AM, Sargen K, Demaine AG, Kingsnorth AN. Investigations of the interleukin 1 gene cluster and its association with acute pancreatitis. Pancreas. 2000; 20 (3): 234-40.

14. Teich N, Bauer N, Mössner J, Keim V. Mutational screening of patients with nonalcoholic chronic pancreatitis: identification of further trypsinogen variants. The American journal of gastroenterology. 2002; 97 (2): 341-6.

15. Ulrich AB, Standop J, Schmied BM, Schneider MB, Lawson TA Pour PM. Species differences in the distribution of drugmetabolizing enzymes in the pancreas. Toxicologic pathology. 2002; 30 (2): 247-53.

16. Dellinger EP, Forsmark CE, Layer P, Levy P, Maravi-Poma E, Petrov MS, et al. Determinant-based classification of acute pancreatitis severity: an international multidisciplinary consultation. Ann Surg. 2012; 256 (6): 875-80.

17. Banks PA, Bollen TL, Dervenis C, Gooszen HG, Johnson CD, Sarr MG, et al. Acute Pancreatitis Classification Working Group. Classification of acute pancreatitis 2012: revision of the Atlanta classification and definitions by international consensus. Gut. 2013; 62 (1): 102-11.

18. Klyaritskaya IL, Rabotyagova YuS. Novye faktory riska razvitija hronicheskogo pankreatita. Krymskij terapevticheskij zhurnal. 2012; (2): 63-69. Russian.

19. Lazarenko VA, Antonov AE. Sovremennoe sostojanie problemy vrednyh privychek kak faktora riska razvitija pankreatita. Social'nye aspekty zdorov'ja naselenija. 2017; 55 (3). Russian.

20. Furtwængler NA, de Visser RO. Lack of international consensus in low-risk drinking guidelines. Drug and alcohol review. 2013; 32 (1): 11-18.

21. Baranov VS, Baranova EV, Ivashhenko TYe, Aseev MV. Genom cheloveka i geny «predraspolozhennosti»: vvedenie v prediktivnuju medicinu. SPb.: Intermedika, 2000; 271 s. Russian.

22. Spicyn VA, Makarov SV, Paj GV, Bychkovskaja LS. Polimorfizm $\checkmark$ genah cheloveka, associirujushhihsja s biotransformaciej ksenobiotikov. Vestnik VOGiS. 2006; 10 (1): 97-105. Russian.

23. Hubacek JA, Zakharov S. Response to 'CYP2E1 Polymorphism and Better Outcome After Methanol Poisoning'. Basic and clinical pharmacology and toxicology. 2015; 117 (1): 3-4.

24. Marzolini C, Paus E, Buclin T, Kim RB. Polymorphisms in human MDR1 (P-glycoprotein): recent advances and clinical relevance. Clinical Pharmacology and Therapeutics. 2004; 75 (1): 13-33.

25. Guo HQ, Zhang GN, Wang YJ, Zhang YK, Sodani K, Talele T, Chen ZS. $\beta$-Elemene, a compound derived from Rhizoma zedoariae, reverses multidrug resistance mediated by the ABCB1 transporter. Oncology reports. 2014; 31 (2): 858-66.

26. Sychev DA, Levanov AN, Shelekhova TV, Bochkov PO, Denisenko NP, Ryzhikova KA, Kozlov AV. The impact of ABCB1 (rs1045642 and rs4148738) and CES1 (rs2244613) gene polymorphisms on dabigatran equilibrium peak concentration in patients after total knee arthroplasty. Pharmacogenomics and Personalized Medicine. 2018; (11): 127.

27. Sychev D, Shikh N, Morozova T, Grishina E, Ryzhikova K, Malova E. Effects of ABCB1 rs1045642 polymorphisms on the efficacy and safety of amlodipine therapy in Caucasian patients with stage I-II hypertension. Pharmacogenomics and personalized medicine. 2018; (11): 157. 